Images du travail, travail des images

$2 \mid 2016$

Les ouvriers et la photographie : de 1945 à nos jours

\title{
Une mise en image du débat philosophique
}

Laurent Garreau

\section{(2) OpenEdition}

Journals

Édition électronique

URL : https://journals.openedition.org/itti/1263

DOI : 10.4000/itti.1263

Éditeur

Université de Poitiers

Référence électronique

Laurent Garreau, "Une mise en image du débat philosophique », Images du travail, travail des images

[En ligne], 2 | 2016, mis en ligne le 01 septembre 2016, consulté le 27 juillet 2021. URL : http://

journals.openedition.org/itti/1263; DOI : https://doi.org/10.4000/itti.1263

Ce document a été généré automatiquement le 27 juillet 2021.

Images du travail, travail des images 


\section{Une mise en image du débat philosophique}

\section{Laurent Garreau}

« Sans titre ».

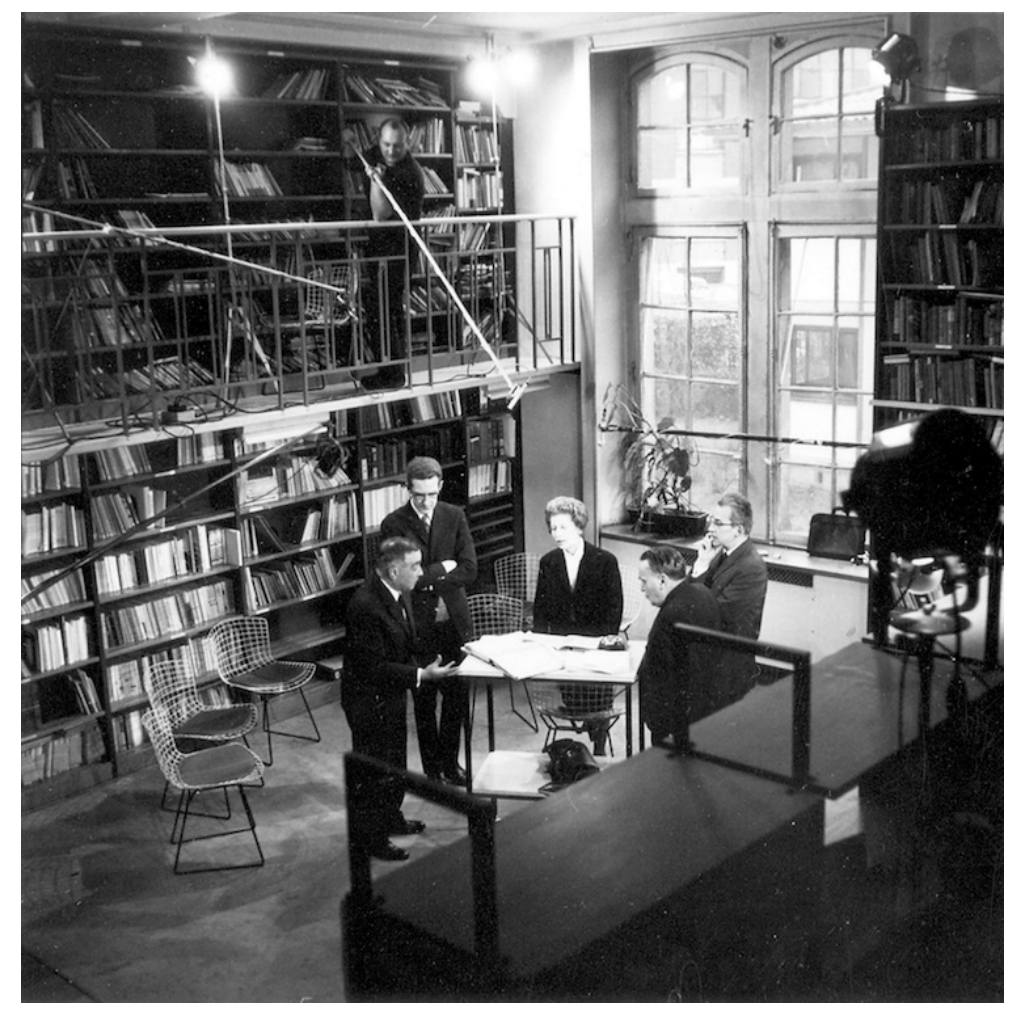

Une mise en image du débat télévisé, une mise en abyme du travail en coulisses. (c) Cadé.

Cette photographie de tournage d'une émission de télévision scolaire est issue du fonds d'archives du Réseau Canopé, dont le siège est situé au Futuroscope. Dans ce fonds 
d'archives, on trouve en effet des reportages photographiques qui rendent compte des conditions de tournage, de production, de réalisation et de réception des émissions de radio-télévision scolaire. Cette image a été prise le $1^{\mathrm{er}}$ mars 1965, lors du tournage de l'émission «Philosophie et vérité » réalisée par Jean Fléchet et diffusée le 27 mars 1965. Les émissions de télévision scolaire faisaient alors l'objet de reportages photographiques destinés à illustrer les fiches pédagogiques ou les documents d'accompagnement publiés dans des revues comme le Bulletin de la Radio-Télévision scolaire ou Documents pour la classe par exemple.

2 Philosophe de formation, j'ai choisi cette photographie car elle illustre la volonté du réalisateur et de la production de donner à voir les coulisses et les moyens de conception d'un langage audiovisuel à des fins pédagogiques. Cette photographie a aussi le mérite de permettre d'approfondir la compréhension des enjeux d'un débat philosophique qui portait sur le thème de la vérité. Cette photographie met en lumière le hiatus entre la vérité au sens philosophique qui est objet de discussion et la déconstruction d'une vérité médiatique toute faite qui laisserait croire que la télévision est un pur système d'enregistrement et de reproduction de la réalité filmée.

3 L'intérêt pour la didactique des images est déterminant dans le travail de l'archiviste et la description documentaire de collections afférant aux œuvres audiovisuelles conservées. On constate le soin particulier pris à la composition du cadre et le souci de mettre en lumière le travail du perchiste et, à travers lui, de ceux qui restent dans l'ombre des personnalités en vedette dans l'émission. En choisissant ce métier de technicien du son plutôt qu'un autre professionnel dans l'équipe de tournage, le photographe veut mettre en avant l'intention philosophique première de l'émission: permettre aux élèves téléspectateurs d'assister à un débat et à un exercice de contradiction philosophique.

4 La vue plongeante sur le parterre de philosophes, la structure à double étage de l'image, la focale et la luminosité artificiellement appuyée sur le visage le plus au centre de la photographie, le contraste entre les positions debout des personnes et l'horizontalité des étagères, tout concourt à la perception d'une composition soignée, picturale, travaillée de cette archive. À ce titre, il importe de montrer les dessous et les alentours du message médiatisé. Il s'agit de neutraliser le mensonge intrinsèque à la mise en scène télévisuelle et de montrer que les cinq "philosophes » ne sont pas les seuls dans la pièce et que ce que l'on voit dans le poste n'est pas réductible à ce qui a été mobilisé pour parvenir à la fabrication de cette émission.

5 Le débat philosophique alors filmé réunit Dina Dreyfus (au milieu des hommes et au centre de l'image), à sa droite Alain Badiou, puis Georges Canguilhem, à la gauche Paul Ricoeur, puis Jean Hyppolite. Plus tard, viendra les rejoindre Michel Foucault. Dans cette photographie, le travail manuel du perchiste, placé au-dessus de la mêlée, fait contraste avec cette émulation intellectuelle, offerte aux téléspectateurs. Néanmoins, la photographie se veut démonstrative et montre une parenté entre ces deux situations professionnelles, à travers la position debout qui est commune aux deux catégories professionnelles mises en scène. Pour être philosophe, il s'agit de ne pas se laisser aller à un relâchement physique et corporel. Il s'agit de se montrer exigeant avec son corps comme avec son esprit. Mais l'admiration du photographe de tournage pour celui qu'il doit considérer comme son pair se traduit par le renversement de la traditionnelle hiérarchie entre métiers manuels et métiers intellectuels. En choisissant un moment où il surplombe la scène filmée, le photographe met à l'honneur le métier de perchiste et 
rend hommage à sa capacité à capter les voix et les débats des philosophes en présence. En dernier ressort, il s'agit bien de montrer que rien ne serait possible sans lui. Par la photographie, la production ambitionne de décrypter l'image télévisée et d'outiller l'éducation aux médias et à l'information.

\section{AUTEUR}

\section{LAURENT GARREAU}

Laurent Garreau est responsable du pôle patrimoine et médiation scientifique du Réseau Canopé. Il est l'auteur d'une thèse de doctorat publié en 2009 aux presses Universitaires de France sous le titre "Archives secrètes du cinéma français". Philosophe de formation, il est chargé de cours en arts du spectacle à l'Université de Paris Ouest. Il publie articles et contributions dans des ouvrages collectifs et des revues dédiées à l'histoire du cinéma, des médias et de la pédagogie audiovisuelle. 